\title{
REVIEW
}

\section{PREVALENCE AND RISK FACTORS OF DEPRESSION IN ETHIOPIA: A REVIEW}

\section{Tesera Bitew}

\begin{abstract}
BACKGROUND: Depression is the most common and disabling mental illness in the globe. It accounts for about $6.5 \%$ of the burden of diseases in Ethiopia. Regardless of its severity and relapse rate, there are no synthesized evidences about its prevalence and potential risk factors in Ethiopia. The aim of this review was thus to synthesize scientific information about the prevalence and potential risk factors of depression in Ethiopia.

METHODS: Out of 37 papers, 31 were collected from PubMed, Medline and Google Scholar electronic databases, and the remaining six from Addis Ababa University, Department of Psychiatry. But, 13 articles were removed after reading the titles; five after reading the abstracts and two after reading the manuscripts and five of them were duplicates. Finally, 12 papers were reviewed and the pooled prevalence was also computed.

RESULTS: The pooled prevalence of depression for the five studies, which had used Composite International Diagnostic Interview (CIDI), was 6.8\%(95\%, CI: 6.4-7.3); but, it increased to 11\%(95\% CI: 10.4-11.5) when three other studies that had used other screening tools were included. Demographic variables such as sex, age, marital status, violence, migration and substance use were associated with depression, but not with economic factors.

CONCLUSIONS: More attention should be given to socio-demographic risk factors and intimate partner violence, since they are potential risk factors of depression. The prevalence of depression in Ethiopia was also found comparable to that of some high-income countries.

KEYWORDS: Depression, risk factors of depression, impact of depression, prevalence, Ethiopia

DOI: http://dx.doi.org/10.4314/ejhs.v24i2.9
\end{abstract}

\section{INTRODUCTION}

The World Health Organization estimated that neuropsychiatric disorders account about a total of $28 \%$ of the global burden of diseases out of which more than one third are caused by depression (1). According to the World Federation of Mental Health report of 2012, depression interferes with the daily life of people and causes pain for both patients and those who care about them (2). Similarly, the Federal Ministry of Health, Ethiopia, stated in its 2012 report that depression was the third leading cause of burden of diseases worldwide; representing $4.3 \%$ of the total disability adjusted life years. It is also predicted to become the second leading cause of the global disease burden by the year 2020 (3).

In Ethiopia, depression contributes to about $6.5 \%$ of the burden of diseases. This is the highest share of burden compared to other forms of mental disorders (4). Numerous researchers and clinicians agree that it is the most disabling problem that also causes increased risk of other health conditions like substance abuse, HIV/AIDS infection and injury $(5,6)$. It decreases the global health score even more than Asthma, Arthritis and diabetes do (7). In line with this, Mogga, et al 2006

Department of Psychology, College of Social Sciences, Debre Markos University

Corresponding Author: Tesera Bitew, Email: tesera110@yahoo.com 
found out in their cohort study that mortality ratio and disability rate were about four times high among depressed individuals than non-depressed people (8). There are also evidences that depression reduces people's coping mechanisms and self-care potentials $(9,10)$.

Regarding its prevalence, the World Health Organization estimated that nearly $15 \%$ of the global population on average suffered from depression at least once in their lives. According to the same report, France and United States had the highest rate of prevalence $(21 \%$ and $19.2 \%$ respectively) while Japan, Germany, Italy and Israel were reported to have the smallest percentages, ranging from under seven to ten percent among the high-income countries.

Although there was not sufficient nationwide survey conducted in Ethiopia to determine the prevalence of depression, a survey done by WHO in collaboration with Jimma University indicated that the prevalence of depression in Ethiopia was $9.1 \%$. On the other hand, the prevalence of depression in Ethiopia was reported to be $5 \%$ according to the Ethiopian Federal Ministry of Health report of 2012. However, there was no source or method described about how the figure was obtained. The remaining information about the prevalence of depression was based on studies in specific settings like Addis Ababa, Butajira, and Hawasa. According to the studies in such specific settings, the prevalence of depression ranges from 0.6 among males in Butajira (11) to 23.6\% among college students in Hawasa (12).

Thus, there was a wide variation among the prevalence rates of depression in Ethiopia as reported by different researchers at different places and time. Such few and discrepant scientific information about depression in Ethiopia with its variation over time and settings has not been systematically reviewed for health decision makers. That is, no review has been conducted yet to identify target vulnerable group in relation to gender, socio-economic and demographic factors and to find out the risk factors of depression.

Therefore, the objective of this systematic review was to synthesize scientific information about the prevalence of depression and the potential risk factors of depression in Ethiopia. The result of the study would help health planners who are interested to formulate intervention strategies to depression in the local context. It is also hoped that the study would benefit researchers who are interested to conduct further research on depressive disorder.

\section{METHODS}

Search strategy: Articles were searched by the terms "Prevalence of Depression in Ethiopia", "Risk Factors of Depression in Ethiopia", "Mental Distress in Ethiopia" and "Prevention of Depression in Ethiopia" from PubMd, MedLine and Google Scholar databases as well as Google searched without restriction of date of publication. Additional articles were collected from the Department of Psychiatry, Addis Ababa University. The Cochrane review data base library was also searched by the terms: "Prevalence of Depression in Ethiopia" and "Risk Factors of Depression in Ethiopia". It was finally learned that there is no any systematic review conducted in Ethiopia in this area.

Eligibility criteria: All literatures not written in English language were excluded because almost all articles in Ethiopia are in English. That is, articles which were not in English and which were not conducted in Ethiopia were excluded. Since the number of articles in Ethiopia is relatively limited, no restriction was made for date of publication. For ease of statistical comparison and analysis, two qualitative studies $(13,14)$ were excluded from the systematic review. In respect to the content, articles that reported the prevalence and risk factors of depression in Ethiopia were included. But, studies that were not conducted in Ethiopia and which did not contain data about prevalence of depression and its risk factors were excluded.

Critical appraisal: The qualities of each of the research reports under systematic review were assessed by using a checklist adapted from Critical Appraisal for Research Papers (15). The checklist focuses on the following criteria: clarity of statement of objectives, the appropriateness of methodology, the appropriateness of research design, justification of selection strategy detail, appropriateness of data collection methods, the relationship between the researcher and the participant, rigor of data analysis, clear statement of findings and discussion of the value of the research. The assessment of each of the studies in 
accordance with the checklist revealed that almost all of the reports were within acceptable quality.

Data extraction and synthesis: Data were first appraised for quality and then extraction was made by using data extraction form. The author developed the data extraction form that suits the specific objective of the systematic review. It included date of publication, name of author, objective of the study, setting, study methods and results. The data was first grouped into themes like prevalence of depression and potential risk factors of depression. Then the report was synthesized based on the themes.

Comprehensive Meta-Analysis Software (Version 2), developed by a team of experts in U.S. and U.K, was used to compute the pooled prevalence of depression first for five studies (11, 16-19), which had used the same diagnostic tool (CIDI). Then, a separate pooled prevalence figure was computed for three studies, which had used Patient Health Questionnaire (PHQ) and SelfReport Questionnaire (SRQ) to diagnose depression. Finally, another prevalence figure was computed for the eight of the studies regardless of the type of instrument they had used to screen depression.

Search Outcomes: The electronic searching of literatures produced thirty-one articles. The other six articles were obtained from Addis Ababa University, Department of Psychiatry. Out of 37 articles, five were found to be duplicates, and 13 were removed after reading the titles; five of them were removed after reading the abstracts and two of them were removed after reading the manuscripts $(13,14)$ because they were not relevant to the objectives of this systematic review. Thus, the review was done one the remaining twelve articles.



Figure 1: Flow chart of study selection 
Characteristics of studies: All studies were conducted in Ethiopia. Though there was no time restrictions during database search, all of them were from 1999-2012 conducted using quantitative methods. Nine of them were crosssectional surveys and the remaining three were cohort studies. No relevant randomized controlled trials and case controls were obtained.

\section{RESULTS}

Prevalence of Depression: The prevalence of depression in Ethiopia varied from $0.6 \%$ among 3016 women in a community-based study in some parts of the country obtained using Composite International Diagnostic Interview (CIDI) (20) to
23.6\% among 1176 students in Awassa identified through PHQ (12). However, a pooled prevalence of five studies, which used CIDI to diagnose depression, indicated that prevalence of depression was $6.8 \%$ (95\%, CI: 6.4-7.3) as shown in figure one. On the other hand, the pooled prevalence of depression for the other three studies $(12,21,22)$ which used PHQ and SRQ to diagnose depression was $18.3 \% \quad(95 \%$ CI: 17.2-19.5). When the prevalence rates in three studies that used PHQ and SRQ were pooled together with the five studies that used CIDI, the pooled prevalence of the eight studies become $11 \%$ (95\%, CI: (10.511.5).
Study name

Deyessa et al, 2010

Hailemariam, et al, 2010

Deyessa, et al, 2008

Kebede \& Alem, 1999

Anas, 1999
Statistics for each study

Event Lower Upper

rate limit limit Z-Value $p$-Value

$\begin{array}{lllll}0.044 & 0.037 & 0.052 & -34.675 & 0.000\end{array}$

$\begin{array}{lllll}0.091 & 0.083 & 0.099 & -46.453 & 0.000\end{array}$

$\begin{array}{lllll}0.044 & 0.036 & 0.053 & -30.563 & 0.000\end{array}$

$\begin{array}{lllll}0.050 & 0.040 & 0.063 & -24.182 & 0.000\end{array}$

$\begin{array}{lllll}0.062 & 0.045 & 0.084 & -16.047 & 0.000\end{array}$

$\begin{array}{llllll}0.068 & 0.064 & 0.073 & -70.996 & 0.000\end{array}$
Event rate and $95 \% \mathrm{Cl}$

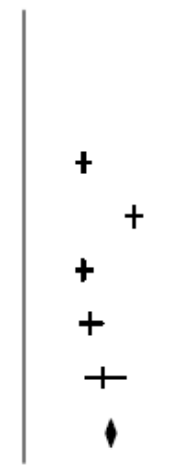

$\begin{array}{llll}-0.25 & -0.13 & 0.00 & 0.13\end{array}$

Figure 2: Pooled prevalence of depression in Ethiopia (CIDI diagnosis)

Studyname

\begin{tabular}{lccccr}
\hline & $\begin{array}{c}\text { Event } \\
\text { rate }\end{array}$ & $\begin{array}{c}\text { Lower } \\
\text { limit }\end{array}$ & $\begin{array}{c}\text { Upper } \\
\text { limit }\end{array}$ & Z-Value & p-Value \\
Deyessa et al, 2010 & 0.044 & 0.037 & 0.052 & -34.675 & 0.000 \\
Hailemariam, et al, 2010 & 0.091 & 0.083 & 0.099 & -46.453 & 0.000 \\
Dejessa, etal, 2008 & 0.044 & 0.036 & 0.053 & -30.563 & 0.000 \\
Kebede \& Alem, 1999 & 0.050 & 0.040 & 0.063 & -24.182 & 0.000 \\
Avas, 1999 & 0.062 & 0.045 & 0.084 & -16.047 & 0.000 \\
Gelaje et al, 2012 & 0.177 & 0.162 & 0.194 & -27.386 & 0.000 \\
Medihin, et al, 2012 & 0.120 & 0.102 & 0.141 & -21.130 & 0.000 \\
Terasaki, et al, 2009 & 0.236 & 0.213 & 0.261 & -17.106 & 0.000 \\
& 0.110 & 0.104 & 0.115 & -77.771 & 0.0000
\end{tabular}

Event rate and $95 \% \mathrm{Cl}$

0.25 0.13

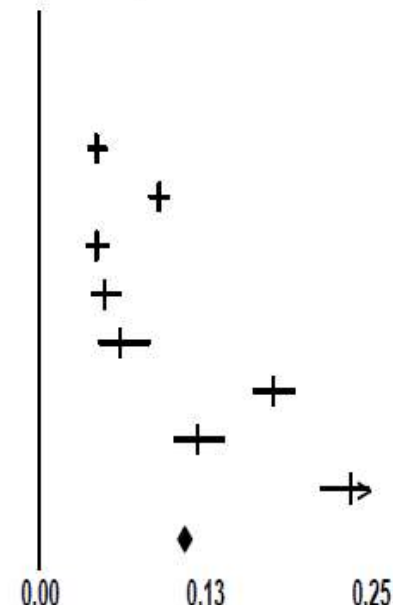

Figure 3: Pooled prevalence of depression in Ethiopia (CIDI, PHQ\&SRQ) 
Potential Risk Factors of Depression in

Ethiopia: The prevalence of depression was also different across different groups. For example, it was highest among pregnant women (22) and among college students in Hawasa (12) as diagnosed by SRQ and PHQ respectively. Similarly, almost all researchers found out that the prevalence of depressive episodes was higher among females than among males $(13,16,17,23$,
24). As shown in table 1 , all papers which focused on the relation between marital status and depression also identified that divorced and widowed women were at a higher risk of depression than unmarried women (OR 4.05 and 4.24 respectively) $(17,18,25)$.

Table 1: Potential demographic risk factors of depression.

\begin{tabular}{|c|c|c|}
\hline $\begin{array}{l}\text { Demographic } \\
\text { Group }\end{array}$ & Demographic groups at higher risk of depression & Author \\
\hline \multirow{4}{*}{ Marital Status } & $\begin{array}{l}\text { Divorced/widowed } 4 \text { times higher than that of } \\
\text { unmarried }\end{array}$ & Hailemariam, et al, 2012 \\
\hline & $\begin{array}{l}\text { Divorced }(8.2 \%) \text { and widowed }(9.4 \%) \text { have higher } \\
\text { rates. }\end{array}$ & Deyessa, 2010 \\
\hline & Divorced and widowed have higher rates. & Deyessa, 2008 \\
\hline & Divorced widowed are at higher risk. & Kebede, et al, 2003 \\
\hline \multirow{5}{*}{ Age } & About 1.1-2.2 times higher for ages $(55-75 /+)$ & Hailemariam, et al, 2012; \\
\hline & Older are at higher risk & Deyessa, et al, 2010 \\
\hline & About 1.4 times higher for ages $(25-+)$ & Deyessa, 2008 \\
\hline & Not associated & Deribew, et al, 2010 \\
\hline & High among people whose age was 35+ & Kebede, 2003 \\
\hline \multirow[t]{3}{*}{ Life Style } & $\begin{array}{l}2.6(2.07-3.17) \text { times higher among frequent and } \\
\text { infrequent heavy drinkers than abstainers }\end{array}$ & Hailemariam, et al, 2012 \\
\hline & High among smokers, people with negative life events & Tarasaki, et al, 2009 \\
\hline & $\begin{array}{l}1.4 \text { times more depression among khat users than non- } \\
\text { users }\end{array}$ & Deyessa, 2008 \\
\hline \multirow{3}{*}{ Residence } & 1.4 (1.04-1.89) times higher among rural than urban & Hailemariam, et al, 2012 \\
\hline & $1.49(0.86-2.61)$ times higher among rural than urban & Deyessa \& Berhane, 2008 \\
\hline & No association with depression & Terasaki, et al, 2009 \\
\hline $\begin{array}{l}\text { Religion and } \\
\text { ethnicity }\end{array}$ & $\begin{array}{l}\text { Depression remains the same for all ethnic and } \\
\text { religious groups }\end{array}$ & $\begin{array}{l}\text { Deyessa, 2008; Tarasaki, } \\
\text { et al, } 2009\end{array}$ \\
\hline
\end{tabular}

Concerning age and substance abuse, it was found that older people (6), substance abusers, and rural people had higher odds of depression than their counterparts $(11,18,23)$. But, prevalence of depression remains the same across religion and
Ethnic groups (25-27). Similarly, educational level and employment had no statistically significant association with depression as reported in most of the papers $(6,11,18,26)$. 
Table 2: Summary of potential socio-economic risk factors of depression

\begin{tabular}{|l|l|l|}
\hline \multicolumn{1}{|c|}{$\begin{array}{c}\text { Socio-economic } \\
\text { Group }\end{array}$} & $\begin{array}{c}\text { Potentially at risk socio-economic } \\
\text { groups to depression }\end{array}$ & \multicolumn{1}{c|}{ Author } \\
\hline \multirow{5}{*}{ Income } & $\begin{array}{l}\text { No significant association with } \\
\text { depression }\end{array}$ & Hailemariam, 2012 \\
\cline { 2 - 3 } & $\begin{array}{l}\text { People with no source of income are } \\
\text { at risk }\end{array}$ & Deribew, et al, 2010 \\
\cline { 2 - 3 } & $\begin{array}{l}\text { Protective factor for depression } \\
\text { (OR<1) }\end{array}$ & Deyessa\&Berhane, 2008 \\
\hline \multirow{2}{*}{$\begin{array}{l}\text { Employment } \\
\text { /occupation }\end{array}$} & $\begin{array}{l}\text { No significant association with } \\
\text { depression }\end{array}$ & Hailemariam, 2012 \\
\cline { 2 - 3 } & No significant association with CMD & Deribew, et al, 2010 \\
\cline { 2 - 3 } Educational level & People with seasonal jobs are at risk & Deyessa, 2008 \\
\hline \multirow{3}{*}{$\begin{array}{l}\text { No significant association with } \\
\text { depression }\end{array}$} & Hailemariam, 2012; Deribew, et al, 2010 \\
\cline { 2 - 3 } & $\begin{array}{l}\text { No significant association with } \\
\text { depression }\end{array}$ & $\begin{array}{l}\text { Deyessa\&Berhane, 2008; Terasaki, et al, } \\
\text { 2009 }\end{array}$ \\
\hline
\end{tabular}

People with more number of chronic diseases and those with a habit of substance abuse were at higher risk of depression (Table 3). Similarly, individuals living with HIV/AIDS taking ART were at higher risk of depression than those not taking ART (Table 3). Finally, people with perceived stigma, females with high parental or intimate partner violence and migrants were at a higher risk of depression.

Table 3: Summary of other potential risk factors of depression

\begin{tabular}{|c|c|c|c|}
\hline Associated Risk factors & Vulne rable Group & Effect size & authors \\
\hline Alcohol drinking status & Substance abusers & $\begin{array}{lll}\mathrm{OR}=1.6, & 95 \% & \mathrm{CI}: \\
1.13-2.28 & & \end{array}$ & Hailemariam, et al, 2012 \\
\hline $\begin{array}{l}\text { Perceived stigma of } \\
\text { PLWHA and perceived } \\
\text { general health }\end{array}$ & $\begin{array}{l}\text { who perceive more } \\
\text { stigma and } \\
\text { perceiving } \\
\text { unhealthy }\end{array}$ & OR 2.0 CI: $1.4,2.8$ & Deribew, et al, 2010 \\
\hline ART & not taking ART & (OR 1.8 CI: $0.9,30)$ & Deribew, et al, 2010 \\
\hline $\begin{array}{l}\text { Intimate } r \text { partner } \\
\text { violence, gender based } \\
\text { violence and childhood } \\
\text { experience of parental } \\
\text { violence. }\end{array}$ & $\begin{array}{l}\text { People who faced } \\
\text { any form of } \\
\text { violence }\end{array}$ & $\begin{array}{l}\text { Consistently high } \\
\text { but, different in } \\
\text { different studies }\end{array}$ & $\begin{array}{l}\text { Deyesa, 2010; Yigzaw, et al., 2004); } \\
\text { Tarasaki, et al, 2009; Tdege, 2008); } \\
\text { Gelaye, 2009; Tadege, et al, 2008; } \\
\text { Gelaye, et al, 2009; Nicodimos, } \\
2009 .\end{array}$ \\
\hline $\begin{array}{l}\text { Number of chronic } \\
\text { diseases }\end{array}$ & \begin{tabular}{lr}
\multicolumn{2}{l}{ Associated with } \\
higher risk of \\
depression
\end{tabular} & $\begin{array}{l}\text { OR=1.7, 95\%, CI: } \\
1.1-2.9\end{array}$ & $\begin{array}{l}\text { Deribew, et al, 2010; Hailemariam, } \\
\text { et al, 2012; Deysessa, 2009; Tadege, } \\
\text { et al, 2008; Gelaye, } 2009\end{array}$ \\
\hline Migration & Migrated people & 3 times higher & Fenta, et al, 2004 \\
\hline $\begin{array}{l}\text { Stressful life events, } \\
\text { food insecurity }\end{array}$ & $\begin{array}{lr}\text { People } & \text { with } \\
\text { stressful } & \text { life } \\
\text { experiences } & \\
\end{array}$ & No effect size & Tarasaki, et al, 2009 \\
\hline
\end{tabular}




\section{DISCUSSION}

Different rates of prevalence have been reported by different researchers. But, pooled prevalence of depression of eight studies, $11 \%$ (95\%, CI: 10.4-11.5), was close to prevalence reported in a cross sectional study which was conducted from Demographic Health Survey data by Hailemariam (2012) (18). This cross-sectional study was conducted on 4,925 adult respondents who were taken from various regions of Ethiopia. It indicated that the prevalence of depression in the country was $9.1 \%$ (18). The pooled prevalence of depression became the highest i.e. $18.3 \%(95 \%$ CI: 17.2-19.5) when PHQ and SRQ were used to screen, while it was $6.8 \%$ when CIDI was used to diagnose. This was because these self-reported screening tools are more sensitive than diagnostic tools like CIDI especially at lower cut off points.

The pooled prevalence of depression in eight studies (11\%) was also equivalent with the prevalence of depression in high-income countries like Japan, Germany, Italy and Israel as reported in WHO (2001). It was close to that of the international figure and better represents the prevalence in the whole country as the samples were taken from various regions of Ethiopia. On the other hand, the prevalence rate reported by the Ethiopian National Mental Health Association in 2012 has no sufficient sources of evidences. Since the remaining studies were conducted in specific settings, they were not generalizable to the whole country.

In almost all papers, it is reported that females in general and divorced and widowed women in particular had higher risk of depression than unmarried/married women and males. The suggested reasons for high rate of prevalence among females compared to males were sex hormones having some influences on depression. However, social researchers focus on social norms for males and females (gender issues) as additional reasons. They argue that parents unintentionally become more restrictive to their daughters than to their sons. This makes their daughters vulnerable to depression by reducing senses of self-control and self-esteem.

As reported in most of the papers, educational level and employment were not statistically associated with depression $(6,18,25,26)$. The reasons for this result could also be either difficulty in measurement of level of socioeconomic variables as the authors also pointed out in their limitations, or the respondents' bias in reporting their level of income. Such respondent bias in reporting their level of income occurs especially when respondents fear income tax to be levied on them or when they expect aid from the government or when they both fear income tax and expect aid from the government. Generally, the relation between socio-economic factors and depression still requires further investigation as it also contradicts the findings in western countries which revealed prevalence of depression was relatively higher in high income countries than in middle and low-income countries.

Other consistently reported potential risk factors of depression include chronic illness like HIV/AIDS, habit of substance abuse, stigma, intimate partner violence, migration and parental violence. These findings were similar with the study results in other western countries. The findings imply at least some universality of the risk factors of depression across the globe. That is depression is prevalent in all countries regardless of color and level of income. Generally, the prevalence of depression in Ethiopia is relatively high and comparable to that of other countries. Therefore, future intervention strategies should focus on family and intimate partner violence, gender-based violence and socio-demographic factors like gender, age and marital status which are the main risk factors. Nevertheless, due to scarcity of published and indexed articles about depression in Ethiopia, the review was conducted on the existing few literatures with their shortcomings. As a result, the prevalence of depression reported here was a better approximation than an accurate figure.

\section{ACKNOWLEDGMENTS}

I am highly indebted to Michael Bonstein, the manager of CMA Software, for providing with free comprehensive meta-analysis software. I would also like to thank my instructor, Dr. Charlotte Hanlon (Associate Professor, Addis Ababa University), for her constructive feedback and careful comments. My gratitude also goes to Sualih Mussa, a language expert, for carefully editing this manuscript. Finally, I would like to thank my family and friends for their persistent 
appreciation and moral support while I was preparing this document.

\section{REFERENCES}

1. WHO. Mental health Report: new understanding, new hope. 2001.

2. WFMH. Depression: A Global Crisis World Mental Health Day. 2012.

3. FMOH. National Mental Health Strategy of Ethiopia (2012/13 -2015/16), Addis Ababa. 2012.

4. Abdulahi A, Damen H \& Dereje K. Burden of Disease Analysis in Rural Ethiopia. Ethiopian Medical Journal, 2001;39: 271-281.

5. Alemu H, Tsui A, Ahmed S, \& Shewamare A. Effect of depressive symptoms and social support on weight and CD4 count increase at HIV clinic in Ethiopia. AIDS care, 2012;24(7):866-76.

6. Deribew A, Yohannes H, Apers L, Abebe G, Duchateau L \& Colebunders R. Common mental disorders in TB/HIV co-infected patients in Ethiopia. BMC Infectious Diseases, 2010;10:201.

7. Marina M. Depression: A Global Crisis. World Federation for Mental Health. 20th Anniversary of World Mental Health Day. 2012.

8. Mogga S PM, Alem A, Kebede D, Stewart R, Glozier N \& Hotopf M. Outcome of major depression in Ethiopia: population-based study. Br J Psychiatry, 2006;189 241-6.

9. Bonari L, Pinto N., Einarson A., Steinereir M, Koren G. Perinatal Risks of Untreated Depression During Pregnancy. Can J Psychiatry, 2004;49(11): 726-735.

10. Senturk V, Hanlon C, Medihin G, Dewey M, Araya M, Alem A, Prince M, Stewart R. Impact of Perinatal somatic and common mental disorder symptoms on functioning on Ethiopian Women: The P-MaMiE population based cohort study. Journal of Affective Disorders. 2012;136:340.

11. Deyessa N, Berhane Y, Alem A, Hogberg U, Kullgren. Depression among women in rural Ethiopia as related to socioeconomic factors: a community-based study on women in reproductive age groups. Scand J Public Health, 2008;36(6):589-97.
12. Terasaki D, Gelaye B, Berhane Y, Williams MA. Anger expression, violent behavior, and symptoms of depression among male college students in Ethiopia. BMC public health; 2009;9:13.

13. Alem A, Araya M, Kebede D \& Kullgren G. How are mental disorders seen and where is help sought in a rural Ethiopian community? A key informant study in Butajira, Ethiopia. Acta psychiatrica Scandinavica Supplementum, 1999;397:40-47.

14. Hanlon C, Wondimagegn D, Alem A \& Prince M. Between life and death: exploring the sociocultural context of antenatal mental distress in rural Ethiopia. Arch Womens Ment Health, 2010;13(5):385-93.

15. Sullivan. Critically Appraised Topic (CAT) Checklist and Guide Questions 2008.

16. Awas M, Kebede D, Alem A. Major mental disorders in Butajira, southern Ethiopia. Acta psychiatrica Scandinavica Supplementum, 1999;397:56-64.

17. Deyessa N. Intimate partner violence and depression among women in rural Ethiopia. Umeå University Medical Dissertations 2010, 2010; New Series No 1335.

18. Hailemariam $\mathrm{S}$. The prevalence of depression and associated factors in Ethiopia: findings from the National Health Survey International Journal of Mental Health Systems, 2012;6(23):6-23.

19. Kebede D, Alem A. Major mental disorders in Addis Ababa, Ethiopia. II. Affective disorders. Acta psychiatrica Scandinavica Supplementum, 1999;397:18-23.

20. Deyessa N, Berhane Y, Alem A, Hogberg U, Kullgren G. Depression among women in rural Ethiopia as related to socioeconomic factors: a community-based study on women in reproductive age groups. Scandinavian journal of public health, 2008;36(6):589-97.

21. Gelaye B, Arnold D, Williams MA, Goshu M, Berhane Y. Depressive symptoms among female college students experiencing genderbased violence in Awassa, Ethiopia. Journal of interpersonal violence, 2009;24(3):464-81.

22. Medihin G, Hanlon C, Dewey M, Alem A, Tesfaye F, Lakew Z, et al. The effect of Maternal common mental disorders on infant undernutrition in Butajira, Ethiopa: P-MaMiE study. BMC Psychiatry, 2010;10(32). 
23. Deyessa N B, Emmelin M, Ellsberg M, Kullgren $\mathrm{G}$ \& Högberg U. Joint effect of maternal depression and intimate partner violence on increased risk of child death in rural Ethiopia. Archives of disease in childhood, 2010;95(10):771-5.

24. Kebede D, Alem A, Rashid E. The prevalence and socio-demographic correlates of mental distress in Addis Ababa, Ethiopia. Acta psychiatrica Scandinavica Supplementum. 1999;397:5-10.

25. Deyessa B. Depression among women in rural Ethiopia as related to socioeconomic factors: A community-based study on women in reproductive age groups. Scand J Public Health, 2008;2008:36(589).

26. Terasaki D, Berhane Y \& Williams M. Anger expression, violent behavior, and symptoms of depression among male college students in Ethiopia. BMC public health, 2009;12(9):13.

27. Hadley C, Tessema F, Cowan J, Asefa M \& Galea S. Food insecurity, stressful life events and symptoms of anxiety and depression in east Africa: evidence from the Gilgel Gibe growth and development study. Journal of epidemiology and community health, 2008;62(11):980-6.

28. Nicodimos $S$, Williams $M$ \& Berhane $Y$. Associations betweenwitnessing parental violence and experiencing symptoms of depression among college students. East African journal of public health, 2009;6(2):184-90.

29. Alemu H, Haile Mariam D, Tsui A, Ahmed S, Shewamare A. Effect of depressive symptoms and social support on weight and CD4 count increase at HIV clinic in Ethiopia. AIDS care, 2012;24(7):866-76.

30. Hanlon C, Wondimagegn D, Alem A \& Prince M. Postnatal mental distress in relation to the sociocultural practices of childbirth: an exploratory qualitative study from Ethiopia. Soc Sci Med, 2009;69(8):1211-9.
31. Mekonnen D, Kebede Y. The prevalence of suicidal ideation and attempts among individuals attending an adult psychiatry outpatient clinic in Gondar, Ethiopia. African health sciences, 2011;11(1):103-7.

32. Waddell C \& Hua J. Preventing and Treating Depression in Children and Youth. A Research Report Prepared for the British Columbia Ministry of Children and Family Development, University of British, Columbia. 2004.

33. Kebede D Alem A, Deyassa N, Shibre T, Negash A \& Beyero T. Major mental disorders in Addis Ababa, Ethiopia: Affective disorders. Acta Psychiatr Scand Suppl, 1999;397:18-23.

34. Mekonnen D \& Kebede Y. The prevalence of suicidal ideation and attempts among individuals attending an adult psychiatry outpatient clinic in Gondar, Ethiopia. Afr Health Sci, 2011;11 (1):103-77.

35. Holon M. Cognitive and Behaviour Therapy in the Treatment and Prevention of Depression. Academic Psychiatry, 2011;28:263-6.

36. Judith T. Mental health screening in women with genital tract fistulae. BJOG: an International Journal of Obstetrics and Gynaecology, 2005;112:1328-30.

37. Kebede D Allem A, Deyassa N, Shibre T, Negash A \& Beyero T. Socio-demographic correlates of depressive disorder in Butajira, rural Ethiopia. Cent Afr J Med, 2003;49 (78):78-83.

38. Tadegge A. The mental health consequences of intimate partner violence against women in Agaro Town, southwest Ethiopia. Trop Doct, 2008;38(4):228-9.

39. Yigzaw T. Domestic violence around Gondar in Northwest Ethiopia. Ethiop J Health Dev, 2004; 18 (3). 